\section{AB1099 EVALUATION OF DIFFERENT FLUORESCENCE- OPTICAL IMAGING (FOI) ASSESSMENT METHODS TO DIFFERENTIATE CLINICAL PSORIATIC ARTHRITIS FROM PSORIASIS}

L. Haan ${ }^{1,2,3}$, U. Henkemeier ${ }^{1,2,4}$, A. C. Foldenauer ${ }^{1,2}$, H. Burkhardt ${ }^{1,2,3,4}$ F. Behrens ${ }^{1,2,3,4}$, M. Köhm ${ }^{1,2,3}$. ${ }^{1}$ Fraunhofer IME Translational Medicine and Pharmacology, Frankfurt, Germany; ${ }^{2}$ Fraunhofer Cluster of Excellence Immunemediated Diseases CIMD, Frankfurt, Germany; ${ }^{3}$ Goethe-University Frankfurt, Frankfurt, Germany; ${ }^{4}$ Centre of Innovative Diagnostics and Therapeutics Rheumatology/Immunology, Frankfurt, Germany

Background: Psoriasis (Pso) is one of the most common chronic inflammatory skin diseases in Europe. Psoriatic arthritis (PsA) is closely associated to Pso whereas the skin manifestation appears usually years before PsA-related symptoms emerge. Up to $30 \%$ of Pso patients develop PsA, but there is no clear correlation between disease duration of Pso and PsA development. In early PsA, changes in synovial vascularisation combined with increased expression of proangiogenic factors appear first. Therefore, imaging biomarkers for detection of changes in vascularisation might be useful for early detection of musculoskeletal disease. Fluorescence-optical imaging (FOI) is an indocyanine green (ICG) tailored method to detect microvascular changes in the hands using ICG kinetics over $360 \mathrm{sec}$. Different methods for assessment of FOI are available. It has not yet been demonstrated to what extent these methods can be used to differentiate psoriasis from psoriasis arthritis.

Objectives: To evaluate different reader dependent assessment methods to evaluate $\mathrm{FOI}$ in psoriasis and psoriatic arthritis.

Methods: FOI data (clinical PsA $n=137$, PsO without PsA $n=202$ ) from an observational prospective multicentre trial in Germany was used for manual assessment of the films using two different published assessment methods:(1) FOI activity score (FOIAS) and (2) individual characteristics of ICG kinetics. For (1) FOIAS, the levels of signal enhancement were scored using a scoring system from 0 to 3 ( $0=$ no enhancement, $3=$ strong enhancement) per joint as well as an assessment of the summation picture. (2) Kinetics were determined by joint-related signal enhancements as well as by ICG related flow-on and flow-off behaviour. Time to the first appearance of the signal, the time to the maximum enhancement and the time to the end of the signal were determined. Results: By use of (1) FOIAS, the maximum score (overall signals of all joints assessed by FOIAS) showed a significant difference $(p=0.0075)$ between PsA (mean 4.76) and PsO (mean 3.84). (2) Time to global maximum showed no significant difference (PsA mean 91.1 sec vs PsO 92.6 sec). Moreover, the mean time to maximum and clearance of ICG did not differ between the two diseases. The duration of the 3 phases of kinetic (phase 1: flow-in, phase 2: stable, phase 3: clearance) was $52.4 \mathrm{sec}, 180.2 \mathrm{sec}$ and $119.8 \mathrm{sec}$ for PsA and $57.6 \mathrm{sec}, 186.0 \mathrm{sec}$ and $130.5 \mathrm{sec}$ for PsO with an earlier phase 2 and 3 for PsA by trend. The most frequently affected joints in PSA (affected > 10\%): PIP 3 right and PIP 5 right.

Conclusion: $\mathrm{FOI}$ is a sensitive method to detect changes in microvascularisation in the hands. The use of the manual FOIAS is able to differentiate significantly between PsA and PsO patients by comparison of the sum of scores over all joints (maximum score). The assessment of ICG kinetics is limited to discriminate between musculoskeletal and joint disease, differentiation of diseases is only seen by trend. Both methods characterize disease states differently. A combination of both methods might be useful to increase the potential of manual assessment of $\mathrm{FOI}$ signals.

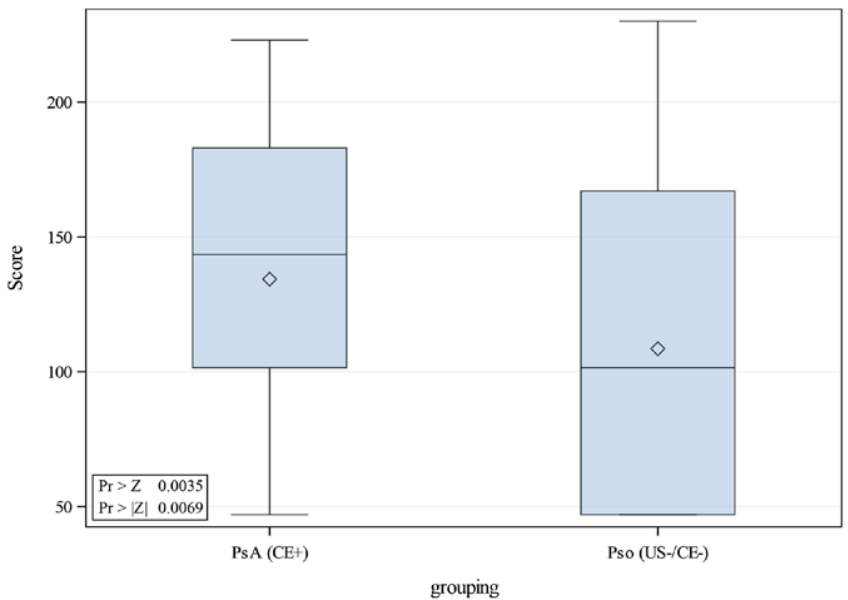

Figure 1. Maximum sum score of FOIAS in PsO and PsA patients ( $p=0.0075$ in two-sided t-test)
Disclosure of Interests: Luis Haan: None declared, Ulf Henkemeier: None declared, Ann Christina Foldenauer: None declared, Harald Burkhardt Grant/ research support from: Pfizer, Roche, Abbvie, Consultant of: Sanofi, Pfizer, Roche, Abbvie, Boehringer Ingelheim, UCB, Eli Lilly, Chugai, Bristol Myer Scripps, Janssen, and Novartis, Speakers bureau: Sanofi, Pfizer, Roche, Abb vie, Boehringer Ingelheim, UCB, Eli Lilly, Chugai, Bristol Myer Scripps, Janssen, and Novartis, Frank Behrens Grant/research support from: Pfizer, Janssen Chugai, Celgene, Lilly and Roche, Consultant of: Pfizer, AbbVie, Sanofi, Lilly, Novartis, Genzyme, Boehringer, Janssen, MSD, Celgene, Roche and Chugai, Michaela Köhm Grant/research support from: Pfizer, Janssen, BMS, LEO, Consultant of: BMS, Pfizer, Speakers bureau: Pfizer, BMS, Janssen, Novartis DOI: 10.1136/annrheumdis-2020-eular.5351

\section{AB1100 \\ PERFORMANCE OF MAGNETIC RESONANCE IMAGING FOR DETECTING SACROILIITIS IN EARLY} STAGES OF SPONDYLOARTHRITIS

F. Ladeb ${ }^{1}$, D. Ben Nessib ${ }^{2}$, M. Bouaziz' ${ }^{1}$, W. Hamdi ${ }^{2}$, E. Labbene ${ }^{1}$,

K. Maatallah ${ }^{2}$, H. Riahi ${ }^{1}$, M. M. Kchir ${ }^{2}{ }^{1}$ Kassab Institute of Orthopedics, Radiology, Mannouba, Tunisia; ${ }^{2}$ Kassab Institute of Orthopedics, Rheumatology, Mannouba, Tunisia

Background: In view of the limited accuracy of clinical evaluation to recognize sacroilitis, several imaging techniques such as conventional radiographs, scintigraphy, ultrasound (US), computed tomography (CT) and magnetic resonance imaging (MRI) have been used to examine the sacroiliac joints (SIJ).

Objectives: The aim of this study was to assess the performance of MRI for detecting sacroilitis in early stages of spondyloarthritis (SpA).

Methods: This cross-sectional prospective monocentric double-blind study included 57 patients consulting for symptoms suggestive of SpA during more than 3 months between February 2014 and February 2017. Patients with conventional radiograph showing a confirmed sacroilitis (grade 3 or 4) were not included. After clinical examination and blood sampling, eligible patients underwent MRI of SIJ. MR images were interpreted by 2 experimented musculoskeletal radiologists blinded to clinical and laboratory data. Two professors in rheumatology blinded to radiologists conclusions, analyzed clinical data, laboratory tests, HLA typing, X-rays and MR images and divided the patients into 2 groups: confirmed non radiographic $\mathrm{SpA}$ (nr-SpA) or no SpA. This classification was considered as the gold standard when analyzing the results.

Results: Fifteen men and 42 women were enrolled. The mean age at inclusion was $39.75 \pm 11$ years [17-59]. The mean duration from the first symptom was $47 \pm 39$ months [6.6-180]. Forty-three patients were assessed as nr-SpA (75.4\%) and 14 patients as no SpA (24.6\%). Thirty-three percent of patients were HLA B27 positive. Totally 22 patients had sacroilitis at MRI, all of them classified as confirmed nr-SpA. Among the $\mathrm{nr}-\mathrm{SpA}$ group, MRI showed bone marrow edema (BME) in $34.9 \%$ of patients and erosions in $44.2 \%$ of patients. Among the patients in whom the diagnosis of SpA was excluded, MRI showed bone marrow edema (BME) in $7 \%$ of patients and erosions in $7 \%$ of patients. A statistically significant association was observed between the presence of sacroilitis at MRI and rheumatologists' diagnosis of SpA $(p=0.001)$. The diagnostic value of MRI lesions is presented in the following table:

\begin{tabular}{lcccc}
\hline & $\begin{array}{c}\text { Sensitivity } \\
(\%)\end{array}$ & $\begin{array}{c}\text { Specificity } \\
(\%)\end{array}$ & $\begin{array}{c}\text { Positive Predictive } \\
\text { Value (\%) }\end{array}$ & $\begin{array}{c}\text { Positive Predictive } \\
\text { Value (\%) }\end{array}$ \\
\hline BME & 34.9 & 92.9 & 93.7 & 31.7 \\
Erosions & 44.2 & 92.9 & 95 & 35.1 \\
MRI conclusion: & 51.2 & 100 & 100 & 40 \\
sacrilitis & & & &
\end{tabular}

Conclusion: SIJ MRI had an excellent specificity for the diagnosis of SpA but a moderate sensitivity. Consequently, some patients in early stages of SpA might be missed by MRI. In addition, we found that diagnostic based solely on BME lacked sensitivity. Detection of erosions in addition to BME enhanced sensitivity (from $34.9 \%$ to $44.9 \%$ ) without changing specificity. Indeed, many recent studies have pointed out the importance of considering structural lesions of SIJ in addition to inflammatory lesions [1, 2].

References:

[1] Weber U, Lambert RGW, Pedersen SJ, et al (2010) Assessment of structura lesions in sacroiliac joints enhances diagnostic utility of magnetic resonance imaging in early spondylarthritis. Arthritis Care Res 62:1763-1771. https:// doi.org/10.1002/acr.20312

[2] Weber U, Jurik AG, Lambert RGW, Maksymowych WP (2016) Imaging in Spondyloarthritis: Controversies in Recognition of Early Disease. Curr Rheumatol Rep 18:58. https://doi.org/10.1007/s11926-016-0607-7

Disclosure of Interests: None declared

DOI: 10.1136/annrheumdis-2020-eular.5137 